\title{
BMJ Open Shared decision-making in the ICU from the perspective of physicians, nurses and patients: a qualitative interview study
}

Nina Wubben (D) , Mark van den Boogaard, JG van der Hoeven, Marieke Zegers

To cite: Wubben $\mathrm{N}$, van den Boogaard M, van der Hoeven JG, et al. Shared decision-making in the ICU from the perspective of physicians, nurses and patients: a qualitative interview study. BMJ Open 2021;11:e050134. doi:10.1136/ bmjopen-2021-050134

- Prepublication history and additional supplemental material for this paper are available online. To view these files, please visit the journal online (http://dx.doi.org/10.1136/ bmjopen-2021-050134).

Received 15 February 2021 Accepted 09 July 2021

\section{Check for updates}

(c) Author(s) (or their employer(s)) 2021. Re-use permitted under CC BY-NC. No commercial re-use. See rights and permissions. Published by BMJ.

Intensive care, Radboudumc, Nijmegen, Gelderland, The Netherlands

Correspondence to Dr Marieke Zegers; marieke.zegers@radboudumc.nl

\section{ABSTRACT}

Objective To identify views, experiences and needs for shared decision-making (SDM) in the intensive care unit (ICU) according to ICU physicians, ICU nurses and former ICU patients and their close family members.

Design Qualitative study.

Setting Two Dutch tertiary centres.

Participants 19 interviews were held with 29 participants: seven with ICU physicians from two tertiary centres, five with ICU nurses from one tertiary centre and nine with former ICU patients, of whom seven brought one or two of their close family members who had been involved in the ICU stay.

Results Three themes, encompassing a total of 16 categories, were identified pertaining to struggles of ICU physicians, needs of former ICU patients and their family members and the preferred role of ICU nurses. The main struggles ICU physicians encountered with SDM include uncertainty about long-term health outcomes, time constraints, feeling pressure because of having final responsibility and a fear of losing control. Former patients and family members mainly expressed aspects they missed, such as not feeling included in ICU treatment decisions and a lack of information about long-term outcomes and recovery. ICU nurses reported mainly opportunities to strengthen their role in incorporating nonmedical information in the ICU decision-making process and as liaison between physicians and patients and family. Conclusions Interviewed stakeholders reported struggles, needs and an elucidation of their current and preferred role in the SDM process in the ICU. This study signals an essential need for more long-term outcome information, a more informal inclusion of patients and their family members in decision-making processes and a more substantial role for ICU nurses to integrate patients' values and needs in the decision-making process.

\section{BACKGROUND}

Shared decision-making (SDM) has been endorsed as the most ethical and appropriate decision-making approach. ${ }^{12}$ SDM is defined as a cooperative process between clinicians and patients and, often in the intensive care unit (ICU), their surrogates that enables a way of healthcare decision-making that combines
Strengths and limitations of this study

- Strengths of our study contain the inclusion of diverse samplings of the three major stakeholder groups for shared decision-making in the intensive care unit, and interviews were held until data saturation was reached.

- Thorough analysis leads to the identification of three overarching themes and corresponding categories.

- A limitation is that clinician participants were recruited from two tertiary centres.

- Views and articulations of experiences are influenced by culture and should be verified in more international qualitative studies.

both the clinician's expertise as well as the patient's values and healthcare goals. ${ }^{34}$

SDM in the ICU is recommended when defining the overall goals of care and when making major treatment decisions that are preference sensitive. $^{2}$ The SDM process should contain as its three main ingredients: information exchange, a deliberation period and making an eventual treatment decision. SDM processes occurring between ICU physicians, ICU nurses and other members of the ICU team are defined as interprofessional SDM. It is recommended to occur before discussions with patients and family members take place, to enable the ICU team to speak as one. ${ }^{5}$ It is associated with more accurate prognoses, reduction of moral distress and a more resilient team. ${ }^{5-9}$ Overall, ICU physicians, ICU nurses and patients and surrogates can be viewed as the three pillars of ICU decision-making.

Though SDM has received a lot of attention by healthcare policymakers as a proponent of a patient's right to self-determination, there is a lack of evidence for associations between SDM interventions and patient outcomes. ${ }^{10} 11$ Moreover, its implementation in healthcare settings is oftentimes not without difficulty. 
There is enormous diversity in care practices influenced by workplace culture and practice style. ${ }^{12}{ }^{13}$ Clinicians also interpret guidelines differently, and, subsequently, do not always follow the recommendations when it comes to information provision. ${ }^{14}{ }^{15}$ In practice, families might not be seen as decision-makers but rather as informants who should be protected from feeling responsible for choices made for a loved one. ${ }^{3}$

While patients and families and clinicians do not always agree when it comes to treatment decision-making, ${ }^{16}$ making family members feel involved in ICU care and treatment decision-making has been shown to reduce fear and anxiety and prepares them in aiding patients during their recovery process. ${ }^{17-21} \mathrm{SDM}$ also increases the likelihood of patients forgoing aggressive care if this is not in line with their care goals, ${ }^{22}$ though caution is warranted when decisions can be influenced by the manner in which complex information about disease and treatment is provided by healthcare professionals as well as cultural context. ${ }^{23}$ SDM interventions are able to improve families' ratings of quality of communication and shorten the ICU length of stay. ${ }^{24}$

By elucidating the views of the three main SDM stakeholder groups in current ICU care, it is possible to elaborate on current ideas about when to incorporate patient and family preferences, when these preferences should be overridden by clinicians and how clinicians can improve their own interprofessional SDM. ${ }^{55-27}$ Therefore, the aim of this study was to explore the views, experiences and needs for SDM in the ICU according to ICU physicians, ICU nurses and former ICU patients and their close family members.

\section{METHODS}

\section{Study design and setting}

This is a qualitative interview study carried out between June 2019 and January 2020 in two tertiary centres. The Consolidated Criteria for Reporting Qualitative Studies guidelines for the design and analysis of this interview study were followed ${ }^{28}$ (see: online supplemental material 1). Decision-making in the ICU between the three stakeholder groups roughly occurs in daily multidisciplinary meetings mainly attended by ICU physicians, in regular family conferences where the presence of the ICU nurse is preferred but not required, ${ }^{29}$ and, more informally, at the bedside.

\section{Participant sampling}

Three groups of participants were interviewed: ICU physicians, ICU nurses and former ICU patients and their close family members. Physicians and nurses were approached within the professional network of the authors (MvdB and MZ) and were sampled purposively to ensure a variety in demographic and professional characteristics. Former ICU patients and their family members were reached through appealing to patient association volunteers as well as an advertisement on the ICU patient association website (www.fcic.nl). As the vast majority of ICU patients survive their stay, ${ }^{30}$ and many studies are focused on the end-of-life patient category, our patient and family member sampling focused on ICU survivors. ${ }^{31-34}$

\section{Patient and public involvement}

Former patients and family members were involved in the preparatory phase of this study. Patient organisation board members and the audience members of a patient organisation symposium were asked for input into the topic of SDM in the ICU, which informed the development of the two semistructured topic guides used in this study (see: online supplemental material 2). Interview participants responded to an advertisement on the ICU patient organisation website.

\section{Data collection}

All interviews took place face-to-face in either of the two tertiary centres. Two researchers conducted the first interview (MZ and NW). All subsequent interviews were conducted by one researcher (NW). Both researchers are trained to conduct interviews and execute interview analysis. Neither of the researchers has clinical training. The main interviewer did not have established relationships with any of the interviewees before study commencement. Interviewees were asked to take part in an interview about their experiences with ICU SDM and ICU decisionmaking in general. The interviewers had not conducted qualitative work regarding this topic before.

The two topic guides were applied to ICU clinicians and former ICU patients and their family members, respectively. Topics in both guides included experiences with SDM in the ICU, wishes for its expansion in the ICU and changes necessary to achieve this. The translated topic guide is read in online supplemental materials 3 and 4). Data were collected until data saturation was reached, in other words, when no new information was identified in the interviews. ${ }^{35}$ Transcripts were not returned to participants for comment.

\section{Data analysis}

All audio recordings were transcribed verbatim by an external professional party and, subsequently, coded using a grounded theory approach, where categories, themes and codes were derived through the analysis of the data. Coding is an interpretative process in which conceptual labels are assigned to data. ${ }^{36}$ Two researchers (NW and MZ) coded four interviews independently, before discussing and agreeing on a coding framework. NW then applied open coding to the remainder of the transcriptions under the general supervision of MZ. Data analysis was performed using Atlas.ti software.

\section{RESULTS}

In total, 29 participants were interviewed: five ICU nurses, seven ICU physicians, nine former ICU patients and eight family members (table 1 ). Former patients and 


\begin{tabular}{llll}
\hline Table 1 & Participant characteristics & \\
\hline $\begin{array}{l}\text { Interview } \\
\text { order }\end{array}$ & $\begin{array}{l}\text { ICU physicians and } \\
\text { nurses }\end{array}$ & Age category & Sex \\
\hline 1 & Intensive care nurse & $<40$ & Male \\
\hline 2 & Intensive care nurse & $40-60$ & Female \\
\hline 3 & Intensivist & $40-60$ & Male \\
4 & Intensivist & $40-60$ & Male \\
\hline 5 & Intensive care nurse & $40-60$ & Female \\
\hline 6 & Intensivist & $40-60$ & Female \\
7 & Intensive care nurse & $>60$ & Male \\
\hline 8 & Intensive care nurse & $40-60$ & Female \\
9 & Intensivist & $40-60$ & Male \\
\hline 12 & Intensivist & $<40$ & Female \\
28 & Intensivist & $40-60$ & Female \\
\hline 29 & Intensivist & $40-60$ & Male \\
\hline
\end{tabular}

\begin{tabular}{|c|c|c|c|}
\hline $\begin{array}{l}\text { Interview } \\
\text { order }\end{array}$ & $\begin{array}{l}\text { Former ICU patients } \\
\text { and their family } \\
\text { members }\end{array}$ & Age category & Sex \\
\hline 10 & $\begin{array}{l}\text { Former patient number } \\
1\end{array}$ & $>60$ & Male \\
\hline 11 & $\begin{array}{l}\text { Spouse of former } \\
\text { patient number } 1\end{array}$ & $>60$ & Female \\
\hline 13 & $\begin{array}{l}\text { Former patient number } \\
2\end{array}$ & $40-60$ & Female \\
\hline 14 & $\begin{array}{l}\text { Former patient number } \\
3\end{array}$ & $>60$ & Male \\
\hline 15 & $\begin{array}{l}\text { Spouse of former } \\
\text { patient number } 3\end{array}$ & $>60$ & Female \\
\hline 16 & $\begin{array}{l}\text { Former patient number } \\
4\end{array}$ & $<40$ & Female \\
\hline 17 & $\begin{array}{l}\text { Former patient number } \\
5\end{array}$ & $<40$ & Female \\
\hline 18 & $\begin{array}{l}\text { Spouse of former } \\
\text { patient number } 5\end{array}$ & $40-60$ & Male \\
\hline 19 & $\begin{array}{l}\text { Former patient number } \\
6\end{array}$ & $40-60$ & Male \\
\hline 20 & $\begin{array}{l}\text { Spouse of former } \\
\text { patient number } 6\end{array}$ & $40-60$ & Female \\
\hline 21 & $\begin{array}{l}\text { Child of former patient } \\
\text { number } 6\end{array}$ & $<40$ & Female \\
\hline 22 & $\begin{array}{l}\text { Former patient number } \\
7\end{array}$ & $>60$ & Female \\
\hline 23 & $\begin{array}{l}\text { Spouse of former } \\
\text { patient number } 7\end{array}$ & $>60$ & Male \\
\hline 24 & $\begin{array}{l}\text { Former patient number } \\
8\end{array}$ & $>60$ & Male \\
\hline 25 & $\begin{array}{l}\text { Spouse of former } \\
\text { patient number } 8\end{array}$ & $>60$ & Female \\
\hline 26 & $\begin{array}{l}\text { Former patient number } \\
9\end{array}$ & $40-60$ & Male \\
\hline 27 & $\begin{array}{l}\text { Spouse of former } \\
\text { patient number } 9\end{array}$ & $40-60$ & Female \\
\hline
\end{tabular}

ICU, intensive care unit.

their family members were interviewed together, making for a total of 19 separate interviews. None of the participants dropped out. The interviews took between 30 and
75 min. Fifty per cent of the ICU clinicians and $41.2 \%$ of the former patients and family members were men. Mean age was 47.7 (SD: 2.6) and 57.4 (SD: 3.5), respectively. Of the nine former patients, five had had a medical admission $(55.6 \%)$, three a planned surgery $(33.3 \%)$ and one an emergency surgery $(11.1 \%)$. The seven ICU physicians had a median of 12.0 years of work experience (IQR: 5.0-20.0), whereas the median number of work experience years was 18.0 (IQR: 11.0-29.5) for the five ICU nurses.

The data analysis resulted in 16 categories from which 3 themes were derived: (1) struggles of ICU physicians (table 2), (2) needs of former patients and family members (table 3) and (3) the role of the ICU nurse (table 4).

\section{Theme l: struggles of ICU physicians}

A total of eight categories (table 2) were identified in this theme: uncertainty and unpredictability of longterm outcomes, responsibility, unwillingness of patients to participate in decision-making, physicians prioritise medical facets, trust in patients and families, physicians fear a loss of control, time and 'acting in a treatment mode' in the case of acute or long-term admissions.

When asked about ICU decision-making and SDM, ICU physicians gravitated towards discussing examples of decisions about end-of-life and stopping treatment. ICU physicians described the uncertainty about long-term health outcomes as one of the main struggles they experienced. They cited literary or anecdotal evidence about unexpected outcomes as a reason for struggling with ICU decision-making, such as a patient's satisfaction with life after losing the ability to walk where they expressed only sorrow at first. They cited feeling the weight of this responsibility when dealing with conflicts with nursing staff about continuing or ending treatment. According to the ICU physicians, these conflicts mainly arise over complex, long-stay patients. While they sometimes were uncertain about continuing treatment themselves, earlier experiences with success stories kept them cautious. They expressed a need for more long-term data on survival and quality of life after ICU treatment.

Physicians described variety among their colleagues about starting discussions around treatment wishes and patient needs, with some expressing doing so in the majority of patients, while others thought that doing this more sparingly was sufficient. Several barriers to explore the wishes and needs of patients were discussed. ICU physicians mentioned experiences with patients and families who did not want to involve themselves in the medical decision-making process. Also reported by clinicians and former patients and families was a varying degree of prioritisation of medical facets in discussions by physicians leading to less attention for 'softer' topics, such as quality of life. Some physicians described that these factors often did not come into play unless the patient's chances of recovery become low. Moreover, physicians applied their own ideas about what constitutes a good 
Table 2 Theme I: categories pertaining to struggles of ICU physicians

\begin{tabular}{|c|c|c|}
\hline Category & Codes & Quote \\
\hline $\begin{array}{l}\text { Uncertainty, } \\
\text { interpretability and } \\
\text { unpredictability } \\
\text { of long-term } \\
\text { outcomes }\end{array}$ & $\begin{array}{l}\text { Lack of long-term outcome } \\
\text { information; more long-term } \\
\text { outcome knowledge causes you } \\
\text { to stop treatment sooner; } \\
\text { long-term uncertainty limits } \\
\text { conversations about continuing } \\
\text { treatment }\end{array}$ & $\begin{array}{l}\text { Physician }(\mathrm{P}) \text { : Overall I think there is an understandable tendency to postpone [decision } \\
\text { making about] problems.(...)Again, the problem is always that uncertainty. The other } \\
\text { day we lost a patient after } 6 \text { weeks of treatment.(...)On the one hand you can say that } \\
\text { we all saw that coming. On the other hand-well, you only know for certain if you've } \\
\text { tried it. }\end{array}$ \\
\hline Responsibility & $\begin{array}{l}\text { ICU physicians have final } \\
\text { responsibility; physician } \\
\text { determines treatment plan; } \\
\text { stopping treatment is always an }\end{array}$ & $\begin{array}{l}\text { P: Look, eventually we are the ones that have to bring the message to the family } \\
\text { when we stop treatment ... and that is our responsibility. So for a nurse it is easier to } \\
\text { question whether we should continue, whereas we really need to do so based on good } \\
\text { and substantial arguments. }\end{array}$ \\
\hline
\end{tabular}
option down the line

\section{Unwillingness Certain types of patients don't of patients to want to be involved in decision- participate in making; older patients; family \\ P: (...)especially older people say: no, you've studied for this - I don't know, you tell me. They just put everything back in your hands. You want to have those people decide for themselves but they're not going to.} decision-making members hold back

Physicians Conversations about continuing prioritise medical treatment are difficult when facets

patients are doing badly; quality the truth. So [talking about quality of life] is 'soft' drivel to many people. of life is a 'soft' topic; medical point of view takes precedence; quality of life not a standard part of multidisciplinary discussions; ICU patients' needs centre around communication and (non-medical) sense of control.

\begin{tabular}{|c|c|}
\hline $\begin{array}{l}\text { Trust in patients } \\
\text { and families }\end{array}$ & $\begin{array}{l}\text { Physicians use own interpretation } \\
\text { of what constitutes good quality } \\
\text { of life; } \\
\text { physicians do not always trust } \\
\text { that patients and families know } \\
\text { what they want; physicians know } \\
\text { patients can change their minds; } \\
\text { well-informed patients make } \\
\text { different choices }\end{array}$ \\
\hline
\end{tabular}

Physicians fear a Family or patient wants loss of control to continue treatment disproportionally; ICU physicians have final responsibility

$\begin{array}{ll}\text { Time } & \text { Admission rush or other time } \\ & \text { constraints limit conversations } \\ & \text { about treatment wishes }\end{array}$

'Treatment mode' Treatment mode limits in acute settings conversations about treatment wishes; stopping treatment is always an option down the line; to admit at all or to discontinue treatment stage).
P: Look, in the end we all prefer talking about the fluid balance and CRP levels. That's

$\mathrm{P}$ : Of course everyone will agree that(a patient's biography)is an important topic, but it will often end up last in discussions. I think that the medical side, prognosis, chance of improvement, what are possibilities or alternatives, etc. is always first. These things don't come up until you start wondering if [continuing treatment is still proportional).

Former patients and their families (PF): (patient with very long admission] I've often called it prison. Everything was decided for me. The theme of my illness was losing all

P: What I used to see, and still see a bit-is that we physicians have our own opinions about what constitutes a good quality of life-in other words, what a good outcome looks like. And we do not look at the patient well enough.

P: Things like what would they have wanted, right-(...)we know that it's proven in literature that people who did not want a certain situation, that when it actually happened to them, they were happy with that outcome(...). So that information - 'he would never have wanted to end up in a wheelchair' or 'he would never have wanted to be dependent', when it happens to you, we are apparently flexible enough in our behaviors and emotions, that we eventually can be very happy, and very happy to be alive. So that information has limited value.

P: (On reasons other physicians might not ask a patient or family's wishes)Not wanting to be surprised with things you might not be able to do. That you're scared of promising something you can't fulfill. It's weird to then not ask the question, but that is a way of doing things. Or fearing totally irrational wishes from people.

$\mathrm{P}$ : The limits are mostly put on by time and space. Sometimes you have a really busy day so you don't have time for it. Then you need to cut back a little on those conversations, because there isn't any time.

P: At the same time it's easier for me to intubate,(...)to start renal replacement therapy - far easier than not starting treatment. So I think that's an important point.(...) Sometimes we use the multidisciplinary discussion to say to each other: are we really still on the right track?(...)And then you sometimes get one-liners like: 'You can always stop [treatment), the patient can always say that they don't want it like this [at a later

$\mathrm{P}$ : I'm convinced that people have an interest in being told there is a chance of an unfortunate outcome.(...)I think it's also to do with that many physicians, due to their nature, are in 'treatment mode', and principally still want to treat. Stopping treatment is not a standard reflex of the average physician. quality of life, while not spending enough time clarifying if a certain patient agreed with their interpretation of a good quality of life. ICU physicians also described doubting wishes expressed by patients and their families, again citing literary evidence and anecdotal experiences with patients changing their mind. They expressed doubts about whether patients and families could actually grasp what certain decision in the ICU could lead to in future. They feared that having families be too involved in ICU decision-making would lead to more medically pointless treatment. Furthermore, the acute setting of the ICU was cited as a struggle in the decision-making process, with the general rush cited as a barrier. A 'treatment mode' was described as a rush-driven attitude where physicians 
Table 3 Theme II: categories pertaining to the needs of former ICU patients and their close family members

\begin{tabular}{|c|c|c|}
\hline Categories & Codes & Quotes \\
\hline $\begin{array}{l}\text { A holistic } \\
\text { approach }\end{array}$ & $\begin{array}{l}\text { ICU patients' needs centre } \\
\text { around communication and } \\
\text { (non-medical) treatment; little } \\
\text { attention for the human behind } \\
\text { the condition; physician coming } \\
\text { to sit next to you to ask you } \\
\text { how you are }\end{array}$ & $\begin{array}{l}\text { PF: Treating me as a human being instead of a patient with some mystery illness-yes, I } \\
\text { would have appreciated that very much, especially now looking back. } \\
\text { PF: Being nicer to you. I've heard it from many patients. There are very little things } \\
\text { someone does when maybe having a bad day at work, but for a patient in such a } \\
\text { situation - that's not normal for you. So those are things that you remember months later, } \\
\text { while the nurse probably doesn't think about it at all. }\end{array}$ \\
\hline $\begin{array}{l}\text { Communication } \\
\text { between medical } \\
\text { staff and patients } \\
\text { and families }\end{array}$ & $\begin{array}{l}\text { ICU patients' needs centre } \\
\text { around communication and } \\
\text { (non-medical) treatment; } \\
\text { patients and families lack a } \\
\text { feeling of control; no attention } \\
\text { for the family }\end{array}$ & $\begin{array}{l}\text { PF: I've noticed that the physicians mainly focus on getting better, while you're still in } \\
\text { a completely different phase. Coordinating those views, I think that's very healthy. The } \\
\text { medical part-they have to decide and give you choices and options, but the human part } \\
\text { you have to coordinate together because otherwise I won't understand your decision at } \\
\text { all.(...)And at some point you think: well, whatever, do it, but if you don't agree mentally } \\
\text { and you feel so weak-I don't think that's good for your physical recovery. }\end{array}$ \\
\hline $\begin{array}{l}\text { Information } \\
\text { about long-term } \\
\text { outcomes }\end{array}$ & $\begin{array}{l}\text { Needs for long-term } \\
\text { information; } \\
\text { information regarding recovery; } \\
\text { answers to standing questions; } \\
\text { well-informed patients decide } \\
\text { differently; better information } \\
\text { provision leads to better } \\
\text { outcomes }\end{array}$ & $\begin{array}{l}\text { PF: My feeling about the ICU is - the onus is on quick action, and survival. But then } \\
\text { there is a long road afterwards and I think there should be more attention to that. Like a } \\
\text { conversation with the partner, or whoever, someone close to the patient to say: what is } \\
\text { important for the patient down the line? } \\
\text { PF: Now l've noticed that the better the aftercare, the better your recovery. } \\
\text { PF: Afterwards it's worse, it seems like. Then it really gets through to you how bad it } \\
\text { could have been-and then immediately how good it has been that you've managed to } \\
\text { prevent that. }\end{array}$ \\
\hline
\end{tabular}

ICU, intensive care unit; PF, formerICU patients and their family members.

do not take enough time to assess whether treatment is still in line with patients' best interests or wishes.

\section{Theme II: needs of former patients and family members}

Four categories (table 3) were identified within this theme, including a holistic approach; feeling included in the medical process and knowing what's coming; information about long-term outcomes and communication between medical staff and patients and families.

Former ICU patients and their families described an overwhelming satisfaction with medical care. Their needs centred around how they remembered being treated in a broader sense. They reported sometimes struggling with lingering feelings and memories. Some recalled feeling seen as a condition rather than a human being, which caused them to feel helpless during their stay. While some had no additional needs with regards to their part in the ICU decision-making process, others' needs focused on two areas: being made to feel included in everyday decisions and being better prepared for their recovery post-ICU. Former patients also reported a sense of lack of control about their ICU care. They expressed that this might have been different if they had felt more included in the decision-making process by being explained why things were being done to them. Especially during longer stays, they cited a frustration with their sense of lack of control regarding their schedule in the ICU that they did not experience once leaving the ICU. Some felt that more integration between the medical and 'human' side was needed. For example, being explained exactly why inserting a catheter was necessary instead of feeling like the insertion was a foregone conclusion. They cited that feeling heard and included was the most important factor, rather than having an equal hand in every and all decisions. Moreover, they described that the long road to recovery post-ICU was sometimes unexpected and they expressed a need for more information. This did not only pertain to physical recovery, but to mental health and emotional recovery and issues regarding returning to the workforce as well. They described different levels of received aftercare post-ICU, and the difference it had made to their recovery.

\section{Theme III: the role of ICU nurses}

Four categories were identified within this theme: the role of the ICU nurse being a liaison and translator between the physician and the patient and their family; questioning ICU physician's decisions to continue treatment; difficulties in communication between physicians and nurses and offering non-medical information to complement ICU decision-making.

Within ICU decision-making, ICU nurses were generally focused on their communication with ICU physicians. They described functioning as a liaison between ICU physicians and patients and their families, mainly due to their continuous presence at the bedside. Both physicians and nurses described the role of the nurse as an advocate for the social context and needs of patients and 
Table 4 Theme III: categories pertaining to the role of ICU nurses

\begin{tabular}{ll}
\hline Categories & Codes \\
\hline Liaison and & Nurse is eyes and ears of the physician; nurse \\
translator between & translates medical world for patient; nurse \\
physician, and & makes sure information is clear after a family \\
patient and family & $\begin{array}{l}\text { conference; sharing vulnerabilities can improve } \\
\text { communication between clinicians }\end{array}$
\end{tabular}

Quotes

ICU Nurse (N): Then after the family conference, you let it sink in, and you start repeating it and repeating it. And you try to use the same words as the physician - because I've noticed families say: I think it's so difficult, one says this and the others says this - but that's because [families] don't understand.

$P$ : What kind of support we need, how the family is doing, how the patient is doing, sleeping, pain - there are a lot of things they have a lot of insight about, yes.

$\mathrm{P}:$ Where I see the nurse is(...)as a translator of what the patient was like at home, who are they, what type of person were they, what is their social safety net like(...). That information is very valuable(...). So I think that their added value is in the clarification of the social context.

$\mathrm{N}$ : That is kind of the role we take on: [translating the family's wishes for the physicians.

Incorporating non-medical information in ICU talking about it when something doesn't feel right; decision-making nurse participation in conversation depends on how assertive they are

$\begin{array}{ll}\begin{array}{l}\text { Difficulties in } \\ \text { communication } \\ \text { between } \\ \text { physicians and } \\ \text { nurses }\end{array} & \begin{array}{l}\text { Cooperation with nurses; } \\ \text { discrepancy of opinion between ICU physicians } \\ \text { and nurses regarding end-of-life care for } \\ \text { complicated cases; } \\ \text { nurse doesn't feel welcome in multidisciplinary } \\ \text { meeting; } \\ \text { ICU nurse feels like they are not being taken } \\ \text { seriously }\end{array} \\ \begin{array}{l}\text { Questioning } \\ \text { physician's } \\ \text { decision to } \\ \text { continue }\end{array} & \begin{array}{l}\text { Conflict arises around complex patients who are } \\ \text { at the ICU for a long time; medical point-of-view }\end{array} \\ \text { takes precedence; whether nurse's point-of-view }\end{array}$

treatment
$\mathrm{N}$ : Yes - [nurses] think it's important to be of value in decision moments. Continuing or not, you know. Of course you need to do so based on

medical information, but also based on the holistic view, and I think we should play a larger part in that, because we also know the family really well.

$\mathrm{N}$ : I think generally it is a very medically-focused decision-making process in which the nurse is heard and listened to(...)but I don't think we have that big of a share in the eventual decision.

P: There are nurses that are well spoken and they'll tell you their stuff. They are there, but they are a minority. Plus, they won't always say it to everyone, because they know some [physicians] won't listen.

$\mathrm{N}$ : Then the next day there was a new [intensivist] that didn't know the patient, but I had been at the bedside the entire day, so I told them [what the previous intensivist and I had decided).(Then they said:)'Well, that wasn't communicated with me, I don't agree with you, we won't do it'. So then you're not heard.

$\mathrm{N}$ : We often feel that when the patient is there for a very long time, and we see them deteriorating - the physicians often think: we can try this and we should approach them, maybe they know something-and then we think: should we do all of this?

$\mathrm{N}$ : I think: there are limits. Sometimes it's enough. If you've done everything-you shouldn't stop based on emotions(...)but other times I think: [recovery)'s just not going to happen.

ICU, intensive care unit; N, ICU nurse; P, ICU physician.

their families to physicians as well as a translator of the sometimes difficult medical 'speak' of physicians. Some nurses reported that they used this role to compensate for the variety in physician communication skills with patients and families. Nurses reported being able to provide context for physicians to incorporate in medical decision-making by giving their insights into the patient and family situation. They generally felt listened to, even if their more holistic points of view were not always incorporated in the eventual medical decision, depending on the ICU physician on call. However, in non-complex, everyday cases, they were generally not troubled by this. They noted difficulties in communication between their two professions depending wholly on the various types of physician and nurse. Assertive nurses made sure their voices were heard but acknowledged that not all of their colleagues have this capability.

Conflicts arose in situations of complex patient cases being in the ICU for a prolonged period of time. The ICU nurse study participants, when asked about ICU decision-making and SDM, gravitated towards discussing these struggles, which predominantly centred around continuing or ending treatment, with physicians oftentimes advocating for the former, while nurses want the latter. They felt this was mostly due to being more affected by complex, poignant cases, due to their continuous presence at the bedside. Within this context, they reported feeling not being taken seriously and feeling blindsided by decisions being made in multidisciplinary meetings dominated by physicians. They felt frustrated with the returning nature of this type of conflict. They urged bridging the gap between physicians and nurses through team building, moral deliberation and sharing vulnerabilities about treatment doubts.

\section{Similarities and differences between stakeholder groups}

Overall, barriers to and struggles with implementing SDM in critical care practice were highlighted by both ICU physicians and ICU nurses. They shared a focus on end-of-life decision-making as the main decision in which SDM should be executed. They cited the practical difficulties surrounding end-of-life decision-making, the 


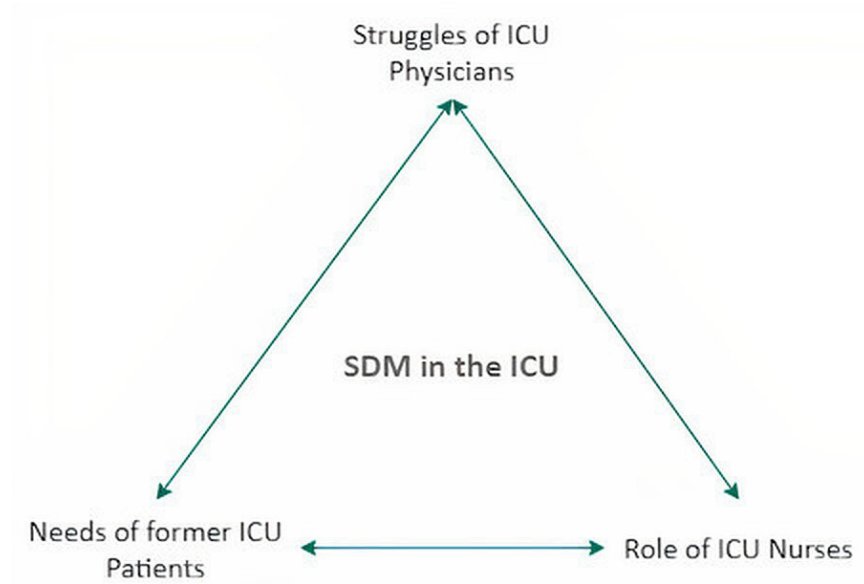

Figure 1 ICU physicians mainly spoke of struggles with implementing SDM in the ICU, while patients and families elaborated on their needs, and ICU nurses talked about how their current role in the ICU decision-making process could be improved. ICU, intensive care unit; SDM, shared decisionmaking.

formal necessities for SDM and their role in it. Clinicians differed when speaking about each other. ICU nurses were very focused on the mediating role and influence the ICU physician and the level in which ICU nurses are invited and able to participate in the SDM process. ICU physicians spoke mostly about the responsibility they felt in imparting the correct information to patients and family members and appeared to not view patients and family members as equal partners in the SDM process.

Patients and their family members offered a different perspective on incorporating SDM. If they had unmet needs, these were mainly focused on wanting a more holistic approach characterised by an open style of communication, wherein they continuously feel part of the decision-making process, although not at the helm (figure 1).

There were several similarities shared across the three stakeholder groups. The results indicated a shared need for more long-term outcome information that could guide both ICU decision-making and help manage future expectations. There was a desire for a more holistic integration of both medical information, as well as contextual information about the patient, such as their quality of life. This is interesting when considering ICU nurses' role as translators, liaisons and advocates for patients' needs. Finally, many of the needs surrounding SDM had a communicative nature.

\section{DISCUSSION}

This qualitative interview study explored the views, experiences and needs for SDM in the ICU experienced by ICU physicians, nurses and former patients and their family members. Interviewees reported struggles, needs and an elucidation of their current and preferred role in the SDM process in the ICU. The three stakeholder groups shared a need for more long-term outcome information and a desire for an integration of medical information with contextual information, paired with a more holistic approach. Many of the needs around SDM in the ICU had a communicative nature.

ICU physicians mainly associated SDM with struggles, such as the uncertainty of the future disease course and feeling pressure because of having final responsibility. They also reported several barriers that prevented them from open communication about wishes of patients or proxies, such as a fear of losing control of the situation. ICU patients and their families reported unmet needs with regards to communication and general (non-medical) treatment, wanting to continuously feel included in the ICU decision-making process, not just during formal meetings. ICU nurses drew a clear picture of their role in the SDM process as a liaison between the physician and patient. They translate medical jargon for patients and advocate for patients' needs and wishes in the decisionmaking process. They reported communication struggles with physicians that limited a more balanced decisionmaking process, in which nurses provide physicians with more information about the wishes and needs of patients.

Earlier literature into the subject shows a focus on decisions pertaining to end-of-life. ${ }^{15} 313738$ This decision is sometimes viewed as one of the main and most difficult decisions to be made in the ICU, so much so that clinician interviewees oftentimes presumed it to be the natural focus point of the interview. Consistently, there was a variety of interpretations regarding what SDM in the ICU looked like. This signals a possible need for training and role models ${ }^{153940}$ to improve both clinician-patient and interprofessional understanding and execution of SDM.

In earlier literature, it is reported that a significant part of patients and family members might not be willing to participate in the decision-making process. ${ }^{41}$ This was reflected in our sample too: not all interviewees had additional needs with regards to decision-making. The needs that were reported here bear some similarities to literature into patient palliative care preferences: mainly, value-focused care aimed at preserving the patient's sense of personhood. ${ }^{42}$ An ICU-based study aimed at improving communication between families and physicians has noted the importance of family members feeling involved in informal physician interactions as well as larger formal ones to establish their role in the decision-making process and improve family empowerment. ${ }^{43}$ Patient and family empowerment through information provision and awareness of the presence of choices are necessary ingredients to improve patient involvement in ICU decision-making. ${ }^{44}$

The findings in this study pertaining to the struggles of physicians confirm findings in earlier studies, especially the difficulties surrounding end-of-life decision-making and the resulting communication struggles between physicians and nurses. ${ }^{143145}$ Clinicians appeared hesitant to surrender control of the decision-making process due to their past experiences as well a lack of trust in the understanding of the situation exhibited by the patient and family members. 
The unavailability of long-term outcome information around survival and quality of life was important to their hesitance in starting conversations around decision-making. Though long-term outcome data collection in the ICU has its challenges, ${ }^{46}$ there is an increase in big data initiatives to tackle the current gaps in knowledge. ${ }^{47}$ For instance, the collection of daily physiologic variable information has been shown to provide an increased understanding and knowledge about the likelihood of ICU survival. ${ }^{48} 49$

Communication struggles reported mainly by the ICU nurses pertaining to decisions to limit treatment have been documented before and appear widespread. ${ }^{50} 51$ Nurses have been described to detect any type of ICU conflict quicker than physicians, ${ }^{52}$ and these conflicts can lead to augmented levels of stress in nurses, ${ }^{53}$ which may increase the incidence of burnout among nurses. ${ }^{54}$ To keep nurses healthy and involved, there is an urgent need for training to improve interprofessional collaboration and communication, perhaps through more frequent moral deliberation meetings. ${ }^{55}$ As was reported in the previous literature, the levels of their involvement in ICU decision-making processes were variable and depended on assertiveness and the type of physician on call. ${ }^{56}$ It, therefore, follows that the information about patient context and background cannot always be sufficiently imparted, though research has shown that nurse involvement in ICU decision-making improves both patients' and nurses' satisfaction-of-care. ${ }^{57}$ To equalise the instances of nurse involvement and provide nurses with a more consistent opportunity to provide their knowledge, it may be beneficial to increase and better define their role during decision-making moments, such as during patient handovers, bedside rounds and multidisciplinary meetings. Earlier literature has indicated that collaborative practice is possible, by, for instance, giving nurses responsibility for providing the physician with day-to-day specific information regarding the patient and signalling when physiological variables are cumulatively out of the normal range, and that it can improve both the clinical outcome as well as the satisfaction levels of ICU clinicians. ${ }^{489} 49458-61$

To ensure a more complete understanding of the complexities of an ICU stay, general practitioners could play a part in information provision to patients and family members in an environment not yet defined by quick action, ${ }^{62}$ while also being able to provide ICU clinicians with context information about the patient. With the large variety in staff attitude to SDM in the ICU, and the interventions surrounding education, prioritisation and resource (re)allocation needed to further implement SDM, the organisation at large should play a role in guideline development and setting a work standard involving SDM. ${ }^{63} 64$

This study offers further elucidation of reasons for the variable levels of uptake of SDM in the ICU. It is a further step towards implementation, paving the way towards a more satisfactory exchange of values between all three stakeholder groups to make preference-based decisions. A strength of this study is the inclusion of all three major stakeholder groups. Our study has several limitations. First, despite our decision to focus on ICU survivors, the many struggles surrounding end-of-life decisions indicate that this is an important ICU decision-making theme. It may, therefore, have been better to include family members of deceased ICU patients as well. Furthermore, though our sample size may be regarded as small, the number of interviews in this study is more than the number suggested by Guest et al..$^{65}$ Also, most of the interviews with ICU physicians and nurses were completed before the interviews with former patients and family members had taken place. Though patient interaction and involvement were discussed in the ICU nurse interviews, this order prevented discussions on more specific findings. However, as the ICU nurses predominantly focused heavily on ICU physicians in their interviews, the impact might be limited. The findings of qualitative research need to be verified for frequency of occurrence in larger samples through questionnaire research. Moreover, our focus on two tertiary centres as the main source of interviewed clinicians may have skewed the results as decision-making culture may differ between ICUs. ${ }^{12}$ However, our findings are in accordance with literature as well as with the preparatory data collected from ICU clinicians and former patients and family members at the national patient organisation symposium (online supplemental material 2). Finally, views and articulations of experiences are influenced by culture. More studies concerning all three main stakeholder groups from different cultures can be a way of elucidating whether the concepts described here are universal or if there are more or different themes.

Though ascertainment of the frequency of these findings might be necessary, the similarities of these results to the literature and preliminary data collection embolden us to say that to further improve SDM implementation there is a need for:

- A more continuous role of patients and family members in ICU decision-making, as individually desired and ascertained.

- Long-term, specific outcome information about survival and quality of life to support SDM discussions.

- A more substantial role for the ICU nurse to ensure their imparting of knowledge about patient context and background during handover meetings, bedside rounds and the multidisciplinary meetings.

- Interventions to improve communication between the three stakeholder groups such as moral deliberation, interprofessional collaboration and the involvement of the general practitioner

\section{CONCLUSIONS}

In the ICU, necessary steps should be taken to implement SDM in a way that satisfies physicians, nurses and patients and their family members. This study gives several recommendations to ensure that all three stakeholder groups can fulfil their role in the SDM process. All in all, there is an essential need for more long-term health outcomes, a more informal inclusion of patients and their family members role in decision-making processes and a more substantial role for the ICU nurse to systematically integrate patients' 
values and needs in the decision-making process. There is a need for interventions that tackle the communication struggles between the three stakeholder groups.

Twitter Nina Wubben @ICresearch_Rumc

Acknowledgements We would like to thank the Dutch ICU patient organisation (FCIC) for their knowledge and help.

Contributors NW, MvdB, JvdH and MZ contributed substantially to the conception of the work. Each author contributed substantially to the design of the work. NW, MvdB and MZ contributed substantially to the acquisition and analysis of the data. Each author contributed substantially to the interpretation of the data. NW drafted the manuscript. Each author contributed substantially to the revision of the work. Each author approved the submitted version. Each author agrees to be personally accountable for the author's own contributions and to ensure that questions related to the accuracy or integrity of any part of the work, even ones in which the author was not personally involved, are appropriately investigated, resolved and the resolution documented in the literature.

Funding This work was supported by Zorginstituut Nederland to last author MZ (2018026879).

Disclaimer Zorginstituut Nederland was not involved in the design of the study, nor with the data collection, analysis, interpretation or writing of the manuscript.

Competing interests None declared.

Patient consent for publication Not required.

Ethics approval The study was approved by the research ethics committee of the Radboud University Medical Center, CMO region Arnhem-Nijmegen (number 2020-6306). Participant information and an invitation for the interview were sent in reply to an informal consent to an interview via e-mail. Additional information about participation was given on request either in the e-mail correspondence or before the start of the interview. An informed consent form was signed before the start of the interview.

Provenance and peer review Not commissioned; externally peer reviewed.

Data availability statement Data are available upon reasonable request. The data used and/or analysed during the current study are available from the corresponding author on reasonable request.

Supplemental material This content has been supplied by the author(s). It has not been vetted by BMJ Publishing Group Limited (BMJ) and may not have been peer-reviewed. Any opinions or recommendations discussed are solely those of the author(s) and are not endorsed by BMJ. BMJ disclaims all liability and responsibility arising from any reliance placed on the content. Where the content includes any translated material, BMJ does not warrant the accuracy and reliability of the translations (including but not limited to local regulations, clinical guidelines, terminology, drug names and drug dosages), and is not responsible for any error and/or omissions arising from translation and adaptation or otherwise.

Open access This is an open access article distributed in accordance with the Creative Commons Attribution Non Commercial (CC BY-NC 4.0) license, which permits others to distribute, remix, adapt, build upon this work non-commercially, and license their derivative works on different terms, provided the original work is properly cited, appropriate credit is given, any changes made indicated, and the use is non-commercial. See: http://creativecommons.org/licenses/by-nc/4.0/.

ORCID iDs

Nina Wubben http://orcid.org/0000-0001-6461-0068

Marieke Zegers http://orcid.org/0000-0002-7472-6184

\section{REFERENCES}

1 Davidson JE, Aslakson RA, Long AC, et al. Guidelines for FamilyCentered care in the neonatal, pediatric, and adult ICU. Crit Care Med 2017:45:103-28.

2 Kon AA, Davidson JE, Morrison W, et al. Shared decision making in ICUs: an American College of critical care medicine and American thoracic Society policy statement. Crit Care Med 2016;44:188-201.

3 Seeber AA, Pols AJ, Hijdra A, et al. How Dutch neurologists involve families of critically ill patients in end-of-life care and decisionmaking. Neurol Clin Pract 2015;5:50-7.

4 Lautrette A, Peigne V, Watts J, et al. Surrogate decision makers for incompetent ICU patients: a European perspective. Curr Opin Crit Care 2008;14:714-9.
5 Michalsen A, Long AC, DeKeyser Ganz F, et al. Interprofessional shared decision-making in the ICU: a systematic review and recommendations from an expert panel. Crit Care Med 2019;47:1258-66.

6 Detsky ME, Harhay MO, Bayard DF, et al. Discriminative accuracy of physician and nurse predictions for survival and functional outcomes 6 months after an ICU admission. JAMA 2017;317:2187-95.

7 Jensen HI, Ammentorp J, Ording H. Guidelines for withholding and withdrawing therapy in the ICU: impact on decision-making process and interdisciplinary collaboration. Heart Lung Vessel 2013;5:158-67.

8 Bruce CR, Miller SM, Zimmerman JL. A qualitative study exploring moral distress in the ICU team: the importance of unit functionality and intrateam dynamics. Crit Care Med 2015;43:823-31.

9 Van den Bulcke B, Vyt A, Vanheule S, et al. The perceived quality of interprofessional teamwork in an intensive care unit: a single centre intervention study. J Interprof Care 2016;30:301-8.

10 Shay LA, Lafata JE. Where is the evidence? A systematic review of shared decision making and patient outcomes. Med Decis Making 2015;35:114-31.

11 Wieringa TH, Rodriguez-Gutierrez R, Spencer-Bonilla G, et al. Decision AIDS that facilitate elements of shared decision making in chronic illnesses: a systematic review. Syst Rev 2019;8:121.

12 Hart JL, Harhay MO, Gabler NB, et al. Variability among US intensive care units in managing the care of patients admitted with preexisting limits on life-sustaining therapies. JAMA Intern Med 2015;175:1019-26.

13 McKenzie MS, Auriemma CL, Olenik J, et al. An observational study of decision making by medical Intensivists. Crit Care Med 2015;43:1660-8.

14 Scheunemann LP, Ernecoff NC, Buddadhumaruk P, et al. ClinicianFamily communication about patients' values and preferences in intensive care units. JAMA Intern Med 2019;179:676-84.

15 Vasher ST, Oppenheim IM, Sharma Basyal P, et al. Physician selfassessment of shared decision-making in simulated intensive care unit family meetings. JAMA Netw Open 2020;3:e205188.

16 Anstey MH, Litton $\mathrm{E}$, Jha N, et al. A comparison of the opinions of intensive care unit staff and family members of the treatment intensity received by patients admitted to an intensive care unit: a multicentre survey. Aust Crit Care 2019;32:378-82.

17 Beeby JP. Intensive care nurses' experiences of caring. Part 2: research findings. Intensive Crit Care Nurs 2000;16:151-63.

18 Gustafson A. Reducing patient uncertainty: implementation of a shared decision-making process enhances treatment quality and provider communication. Clin J Oncol Nurs 2017;21:113-5.

19 Bibas L, Peretz-Larochelle M, Adhikari NK, et al. Association of surrogate decision-making interventions for critically ill adults with patient, family, and resource use outcomes: a systematic review and meta-analysis. JAMA Netw Open 2019;2:e197229.

20 Verharen L, Mintjes J, Kaljouw M, et al. Psychosocial needs of relatives of trauma patients. Health Soc Work 2015;40:233-8.

21 Gross J, Williams B, Fade P, et al. Intensive care: balancing risk and benefit to facilitate informed decisions. BMJ 2018;363:k4135.

22 Gustin AN. Shared decision-making. Anesthesiol Clin 2019;37:573-80.

23 Ozdemir S, Finkelstein EA. Cognitive bias: the downside of shared decision making. JCO Clin Cancer Inform 2018;2:1-10.

24 White DB, Angus DC, Shields A-M, et al. A randomized trial of a Family-Support intervention in intensive care units. N Engl J Med 2018;378:2365-75

25 Fried TR. Communication about treatment options and shared decision making in the intensive care unit. JAMA Intern Med 2019;179:684-5.

26 Curtis JR, Tonelli MR. Shared decision-making in the ICU: value, challenges, and limitations. Am J Respir Crit Care Med 2011;183:840-1.

27 Olding M, McMillan SE, Reeves S, et al. Patient and family involvement in adult critical and intensive care settings: a scoping review. Health Expect 2016;19:1183-202.

28 Tong A, Sainsbury P, Craig J. Consolidated criteria for reporting qualitative research (COREQ): a 32-item checklist for interviews and focus groups. Int J Qual Health Care 2007;19:349-57.

29 Cypress BS. Family conference in the intensive care unit: a systematic review. Dimens Crit Care Nurs 2011;30:246-55.

30 Needham DM, Davidson J, Cohen $\mathrm{H}$, et al. Improving long-term outcomes after discharge from intensive care unit: report from a stakeholders' conference. Crit Care Med 2012;40:502-9.

31 Brooks LA, Manias E, Nicholson P. Communication and decisionmaking about end-of-life care in the intensive care unit. Am J Crit Care 2017;26:336-41.

32 Mehter HM, McCannon JB, Clark JA, et al. Physician approaches to conflict with families surrounding end-of-life decision-making 
in the intensive care unit. A qualitative study. Ann Am Thorac Soc 2018;15:241-9.

33 Martins Pereira S, Fradique E, Hernández-Marrero P. End-of-Life decision making in palliative care and recommendations of the Council of Europe: qualitative secondary analysis of interviews and observation field notes. J Palliat Med 2018;21:604-15.

34 Visser M, Deliens L, Houttekier D. Physician-related barriers to communication and patient- and family-centred decision-making towards the end of life in intensive care: a systematic review. Crit Care 2014:18:604.

35 Pope C, Ziebland S, Mays N. Qualitative research in health care. analysing qualitative data. BMJ 2000;320:114-6.

36 Chapman AL, Hadfield M, Chapman CJ. Qualitative research in healthcare: an introduction to grounded theory using thematic analysis. J R Coll Physicians Edinb 2015;45:201-5.

37 Lautrette A, Darmon M, Megarbane B, et al. A communication strategy and brochure for relatives of patients dying in the ICU. $N$ Engl J Med 2007;356:469-78.

38 White DB, Braddock $\mathrm{CH}$, Bereknyei S, et al. Toward shared decision making at the end of life in intensive care units: opportunities for improvement. Arch Intern Med 2007;167:461-7.

39 Oerlemans AJM, Knippenberg ML, Olthuis GJ. Learning shared decision-making in clinical practice. Patient Educ Couns 2021;104:1206-1212.

40 Lorin S, Rho L, Wisnivesky JP, et al. Improving medical student intensive care unit communication skills: a novel educational initiative using standardized family members. Crit Care Med 2006;34:2386-91.

41 Azoulay E, Pochard F, Chevret S, et al. Half the family members of intensive care unit patients do not want to share in the decisionmaking process: a study in 78 French intensive care units. Crit Care Med 2004;32:1832-8.

42 Nelson JE, Puntillo KA, Pronovost PJ, et al. In their own words: patients and families define high-quality palliative care in the intensive care unit. Crit Care Med 2010;38:808-18.

43 Kalocsai C, Amaral A, Piquette D, et al. "It's better to have three brains working instead of one": a qualitative study of building therapeutic alliance with family members of critically ill patients. BMC Health Serv Res 2018;18:533.

44 Joseph-Williams N, Elwyn G, Edwards A. Knowledge is not power for patients: a systematic review and thematic synthesis of patientreported barriers and facilitators to shared decision making. Patient Educ Couns 2014:94:291-309.

45 Richards CA, Starks H, O'Connor MR, et al. Physicians perceptions of shared decision-making in neonatal and pediatric critical care. Am J Hosp Palliat Care 2018;35:669-76.

46 Wilcox ME, Ely EW. Challenges in conducting long-term outcomes studies in critical care. Curr Opin Crit Care 2019;25:473-88.

47 Geense W, Zegers M, Vermeulen H, et al. MONITOR-IC study, a mixed methods prospective multicentre controlled cohort study assessing 5-year outcomes of ICU survivors and related healthcare costs: a study protocol. BMJ Open 2017;7:e018006.

48 Fidler V, Nap R, Miranda DR. The effect of a managerial-based intervention on the occurrence of out-of-range-measurements and mortality in intensive care units. J Crit Care 2004;19:130-4.
49 Rivera-Fernández R, Nap R, Vázquez-Mata G, et al. Analysis of physiologic alterations in intensive care unit patients and their relationship with mortality. J Crit Care 2007;22:120-8.

50 House S, Havens D, Nurses' HD. Nurses' and physicians' perceptions of Nurse-Physician collaboration: a systematic review. J Nurs Adm 2017;47:165-71.

51 Pecanac KE, Schwarze ML. Conflict in the intensive care unit: nursing advocacy and surgical agency. Nurs Ethics 2018;25:69-79.

52 Studdert DM, Mello MM, Burns JP, et al. Conflict in the care of patients with prolonged stay in the ICU: types, sources, and predictors. Intensive Care Med 2003;29:1489-97.

53 Edwards MP, Throndson K, Dyck F. Critical care nurses' perceptions of their roles in family-team conflicts related to treatment plans. Can J Nurs Res 2012;44:61-75.

54 Bakker AB, Le Blanc PM, Schaufeli WB. Burnout contagion among intensive care nurses. J Adv Nurs 2005;51:276-87.

55 Weidema FC, Molewijk BAC, Kamsteeg F, et al. Aims and harvest of moral case deliberation. Nurs Ethics 2013;20:617-31.

56 Adams A, Mannix T, Harrington A. Nurses' communication with families in the intensive care unit - a literature review. Nurs Crit Care 2017;22:70-80.

57 Puntillo KA, McAdam JL. Communication between physicians and nurses as a target for improving end-of-life care in the intensive care unit: challenges and opportunities for moving forward. Crit Care Med 2006;34:S332-40.

58 Azoulay E, Timsit J-F, Sprung CL, et al. Prevalence and factors of intensive care unit conflicts: the conflicus study. Am J Respir Crit Care Med 2009;180:853-60.

59 Le Blanc PM, Schaufeli WB, Salanova M, et al. Efficacy beliefs predict collaborative practice among intensive care unit nurses. $J$ Adv Nurs 2010;66:583-94.

60 Centofanti JE, Duan EH, Hoad NC, et al. Use of a daily goals checklist for morning ICU rounds: a mixed-methods study. Crit Care Med 2014;42:1797-803.

61 Pronovost P, Berenholtz S, Dorman T, et al. Improving communication in the ICU using daily goals. J Crit Care 2003:18:71-5.

62 van Beusekom I, Bakhshi-Raiez F, de Keizer NF, et al. Dutch ICU survivors have more consultations with general practitioners before and after ICU admission compared to a matched control group from the general population. PLoS One 2019;14:e0217225.

63 Scholl I, LaRussa A, Hahlweg P, et al. Organizational- and systemlevel characteristics that influence implementation of shared decision-making and strategies to address them - a scoping review. Implement Sci 2018;13:40.

64 Giuliani E, Melegari G, Carrieri F, et al. Overview of the main challenges in shared decision making in a multicultural and diverse society in the intensive and critical care setting. J Eval Clin Pract 2020;26:520-3.

65 Guest G, Bunce A, Johnson L. How many interviews are enough?:an experiment with data saturation and variability. Field Methods 2006;18:59-82. 